\title{
Multidisciplinary treatment of patients with diabetes and hypertension: experience of a Brazilian center
}

Thiago Veiga Jardim 1,2,3*, Sayuri Inuzuka', Luan Galvão', Leandra Anália Freitas Negretto', Rogério Orlow de Oliveira', Wanessa Faria Sá ', Haroldo Silva de Souza' ${ }^{1}$ Andrea Crisitina Sousa', Patricia Silva Carneiro ${ }^{1}$, Weimar Kunz Sebba Barroso ${ }^{1}$, Ana Luiza Lima Sousa ${ }^{1}$ and Paulo César Veiga Jardim ${ }^{1}$

\begin{abstract}
Background: Although multidisciplinary treatment is recommended for type 2 diabetes mellitus and hypertension (HTN), there is a lack of scientific literature supporting the hypothesis of extending this treatment strategy to patients with both diabetes and HTN. Aiming to report results of long-term multidisciplinary treatment for these patients and identify strategies to improve their management, we conducted this study.

Methods: Data of patients with diabetes and HTN with regular follow-up visits in a multidisciplinary HTN treatment center from Brazil's Midwest were retrospectively assessed. Patients $\geq 18$ years enrolled in the service by June 2017 with a minimum of three visits were included. Anthropometric, blood pressure (BP), laboratory, pharmacological treatment, lifestyle, and cardiovascular events data were collected from first (V1), intermediate (V2) and most recent (V3) visits to the service. BP $<130 \times 80 \mathrm{mmHg}$, LDL-cholesterol $(\mathrm{LDL}-\mathrm{C})<70 \mathrm{mg} / \mathrm{dL}$ and $\mathrm{HbA} 1 \mathrm{C}<7.0 \%$ were defined as treatment targets. Wilcoxon signed-rank test was used to compare variables along study visits. A linear regression model was built to identify variables associated with better overall patient control.

Results: A total of 162 patients were included (mean age of $56.5 \pm 10.8$ years). Median follow-up time was 60 (IQR 40-109) months, $80.2 \%$ of the sample was female and $83.3 \%$ had no cardiovascular event history. BP, total cholesterol, LDL-C, triglycerides and $\mathrm{HbA1C}$ values showed a significant trend to improve along the study visits $(\mathrm{p}<0.001)$. Growing trend in aspirin $(p=0.045)$ and statins $(p<0.001)$ use was found, in addition to treatment compliance increase ( $p<0.001)$. Significant improvement trends in BP $(p<0.001)$, LDL-C $(p=0.004)$ and HbA1C $(p=0.002)$ control were also found across visits. Control rates of $\mathrm{BP}, \mathrm{LDL}-\mathrm{C}$ and $\mathrm{HbA} 1 \mathrm{C}$ in combination were low in $\mathrm{V} 1, \mathrm{~V} 2$ and V3 $(1.2,1.9$ and $6.8 \%$, respectively), but showed significant improvement trend $(p<0.001)$. Treatment compliance ( $\beta$-coefficient $=1.20 ; 95 \% \mathrm{Cl} 1.07-1.34 ; \mathrm{p}<0.001)$ was positively associated with better overall patients control.

Conclusions: Multidisciplinary treatment of patients with diabetes and HTN significantly improved clinical and laboratory parameters, despite ageing of population evaluated. Although combined control of HbA1C, BP and LDLcholesterol increased along follow-up, management of all these three conditions needs to improve, and focus on treatment compliance should be given to attain this goal.
\end{abstract}

Keywords: Hypertension, Diabetes, Multidisciplinary treatment

\footnotetext{
*Correspondence: thiagoloirin@hotmail.com

${ }^{2}$ Division of Cardiovascular Medicine, Brigham \& Women's Hospital, 75

Francis Street, Boston, MA 02115, USA

Full list of author information is available at the end of the article
} 


\section{Background}

Type 2 diabetes mellitus (T2DM) and hypertension (HTN) are multifaceted clinical syndromes commonly associated [1]. Since both are considered risk factors for coronary artery disease, cerebrovascular disease, renal failure and congestive heart failure, treatment of both conditions is essential [2]. Additionally, patients with diabetes are particularly vulnerable to hypertensive injury, and the coexistence of HTN has a significant impact on the poor prognosis of patients with diabetes because of its synergic deleterious effects on the micro and macro vasculature [3].

Since T2DM and HTN are degenerative diseases, their natural history is expected to be progressive, particularly when people adopt urban westernized lifestyles [4]. As a consequence both diseases tend to aggravate, and patients' management become more challenging as times goes by [5]. Usually, in clinical practice, increasingly worse results in blood pressure (BP), hemoglobin A1C (HbA1C) levels and other risk factors control are found.

Multidisciplinary treatment for T2DM and HTN is recommended by most international guidelines addressing the two conditions individually [6-9], and much of these recommendations are due to the complexity of dealing with these patients. Although it is reasonable to assume that multidisciplinary treatment should be extended to patients with both T2DM and HTN, there is a lack of scientific literature supporting this hypothesis.

Aiming to report the results of a long-term multidisciplinary treatment approach for patients with HTN and T2DM treated in a Brazilian center, to show whether this treatment was capable to improve clinical and laboratory parameters, and additionally to identify strategies to improve the overall management of these patients we conducted this study.

\section{Methods}

Data of patients with both HTN and T2DM with regular follow-up visits in a multidisciplinary HTN treatment center from Brazil's Midwest were retrospectively assessed.

The center has been conducting its activities for more than 25 years, dedicated to hypertensive patients' care, health professional's teaching and research. The multidisciplinary team consists of physicians (general practitioners, cardiologists, endocrinologists and nephrologists), nurses, dietitians, physical therapists, physical education instructors, psychologists and musical therapists. Aiming to improve treatment compliance and reduce loss of follow-up, the maximum interval between each patient appointment is 3-months. Additionally, educational and health promotion activities are routinely performed with the patients [10]. Since the beginning of this multidisciplinary service, consultations have been registered in a standardized form. All healthcare professionals directly involved in patients care are routinely trained to fill this form, ensuring data reliability and reproducibility throughout the follow-up years [11].

This study included all patients with T2DM and HTN aged 18 years and older enrolled in the service by June 2017. A minimum of three visits to the service reported in the medical record was also required.

Hypertension was defined according to the 7th Brazilian Guideline of Arterial Hypertension (chapter 2): (1) office BP $\geq 140 \times 90 \mathrm{mmHg}$; ambulatory BP monitoring $(\mathrm{ABPM}) \geq 130 \times 80 \mathrm{mmHg}$; (3) home BP monitoring $\geq 135 \times \geq 85 \mathrm{mmHg}$ [12]. Patients receiving HTN treatment were also considered as hypertensives.

Diabetes definition followed the recommendations of the last Guidelines of the Brazilian Society of Diabetes [13]: (1) symptoms of polyuria, polydipsia and weight loss plus casual blood glucose $\geq 200 \mathrm{mg} / \mathrm{dL}$ (casual blood glucose-values obtained at any time of the day regardless of meal times); (2) fasting blood glucose $\geq 126 \mathrm{mg} / \mathrm{dL}$ (diagnosis should be confirmed by repeat testing on another day in case of small blood sugar elevations); (3) 2-h plasma glucose value after a 75 -g oral glucose tolerance test $\geq 200 \mathrm{mg} / \mathrm{dL}$. Diabetes treatment registered in medical records was also considered as diagnosis criteria.

\section{Data collection}

Data from the first (V1), an intermediate (V2) and the most recent visit to the service (V3) were collected, regardless the healthcare professional responsible for the visit. V1 was defined as the first visit to the service after being diagnosed as diabetic. V2 was defined depending on the total number of visits (median point of the total number of visits, regardless the time elapsed between visits). V3 was defined as the most recent visit to the service. Follow-up time between visits was calculated from the differences between visits dates, and the results are given in months.

The following data were collected from medical records:

\section{Anthropometric data}

Weight, height and body mass index (BMI) calculated using the Quetelet formula (BMI = weight in $\mathrm{kg} / \mathrm{height}^{2}$ in meter).

\section{Blood pressure}

A minimum of three BP measurements, with at least 1-min interval, was taken. All measurements were performed after $5 \mathrm{~min}$ of rest, on the upper limb, with the individual sitting and the arm supported. Appropriate 
cuffs were used depending on arm diameter. Mean values of last two measurements were considered for data analyses. BP measurements were performed with a mercurycolumn manometer until December 2012. From that date on, BP measurements were performed with oscillometric devices (OMRON semi-automatic equipment, model HEM-705CP). This routine was adopted in the service to avoid observer bias.

\section{Laboratory data}

Renal function with creatinine measured in $\mathrm{mg} / \mathrm{dL}$;

Glomerular filtration rate given in $\mathrm{mL} / \mathrm{min}$ and estimated by the MDRD formula [14];

Fasting glycemia and lipid profile: collected after a $12-\mathrm{h}$ fasting, and observing the recommendation of no alcoholic beverage consumption in the preceding $48 \mathrm{~h}$. The enzymatic colorimetric method was used to determine total cholesterol (TC), high density lipoprotein cholesterol (HDL), serum triglycerides (TG) and glycemia. The low density lipoprotein cholesterol (LDL) level was estimated with the Friedewald formula: $\mathrm{LDL}=\mathrm{TC}-(\mathrm{HDL}+\mathrm{TG} / 5)$ [15]. All values are given in $\mathrm{mg} / \mathrm{dL}$.

All tests were performed at the same laboratory, no more than 30 days prior to the visits.

\section{Pharmacological treatment}

Anti-hypertensive drugs: assessing number of agents and use of angiotensin converter enzyme (ACE) inhibitors or angiotensin receptor blocker (ARB).

Diabetes treatment: oral hypoglycemic agents and insulin.

Other drugs: aspirin and statins.

Patients were also asked if they have been compliant to drug treatments since their most recent visit to the center (yes or no).

\section{Lifestyle}

Smoking: current smoker or nonsmoker;

Alcohol consumption: any alcohol consumption since the most recent visit;

Sedentary lifestyle: no leisure physical activity, regardless duration and intensity.

\section{Cardiovascular events}

Acute myocardial infarction (AMI): reported in medical records and confirmed by hospital discharge summary and/or high levels of myocardial necrosis biomarkers;

Angina: reported in medical records and confirmed by hospital discharge summary;
Stroke: reported in the medical record and confirmed by hospital discharge summary and/or imaging exam suggestive of cerebrovascular event;

Coronary artery bypass grafting or angioplasty: reported in the medical record and confirmed by hospital discharge summary, surgeon's report and/or angioplasty report.

\section{Cardiovascular risk estimation}

The 10-year predicted cardiovascular risks were estimated by the Framingham risk function for total cardiovascular disease (CVD) risk [16]. The 10-year cardiovascular event rate for low, intermediate, high, and very high risk categories were respectively: $<10,10-20$, $20-30$, and $>30 \%$.

\section{BP, LDL-cholesterol and diabetes control definitions}

Management of patients at this multidisciplinary center has always been based on national guidelines. The recommendations of these guidelines changed over time, leading to different treatment goals. Since, there was a great variation on visit dates even within V1, V2 and V3, and only minor changes in guidelines recommendations for diabetic patients occurred, we adopted the recommendations of the last Brazilian Guidelines of hypertension (chapter 8) [17], dyslipidemia [18] and diabetes [13] for the analyses.

BP control was defined as systolic blood pressure (SBP) $<130 \mathrm{mmHg}$ and diastolic blood pressure (DBP) $<80 \mathrm{mmHg}$.

LDL control was defined as LDL $<70 \mathrm{mg} / \mathrm{dL}$.

HbA1C control as a proxy for diabetes control was defined as $\mathrm{HbA} 1 \mathrm{C}<7.0 \%$.

\section{Multidisciplinary service set-up}

The medical team assessed symptoms, lifestyle habits and medications being used, performed complete physical examination, interpreted complementary tests and established patient management (pharmacological and nonpharmacological treatments prescription; complementary tests request; and follow-up visits schedule). In addition, if acute clinical decompensation was identified in the medical visit, patients were referred to emergency care or hospitalization.

The nurse team assessed symptoms, vital signs, lifestyle habits and medications being used, in addition to instructing about treatment compliance in both pharmacological and nonpharmacological aspects. They defined the interval of the nurse follow-up appointment and referred patients for medical consultation if clinically necessary or to ensure a maximum interval between two medical visits of 6 months. 
The group of dietitians emphasized nonpharmacological aspects of care, specifically the diet. They collected dietary data and assessed anthropometric data and vital signs. The management was aimed at dietary guidance with emphasis on salt restriction and prescription of diets for patients with diabetes.

The other health care professionals of the service did not conduct formal appointments, but rather a series of educational interventions to promote patients' health. Physical therapists and physical education instructors conducted periodical meetings previously scheduled or met with patients at the waiting room. They emphasized the importance of regular physical activity; discussed preventive measures for injuries and falls; and additionally, they promoted assisted group physical activity for patients. Similarly, the psychology and musical therapy teams acted mainly in the waiting room, providing instructions and interventions aimed at stress reduction and waiting time improvement.

\section{Statistical analysis}

Statistical analysis was performed using the software STATA V14 (StataCorp., College Station, Texas, USA). Continuous variables are presented as mean and standard deviation or median and interquartile range. Categorical variables are presented as $n$ and \%. Paired T-test was used to compare continuous variables and Chi Square test was used to compare categorical ones. The Wilcoxon signed-rank test was used to compare the variables along the study visits and results for the comparisons are presented as p value for trends [19]. A linear regression model was built to identify the variables independently associated to the number of conditions controlled (HTN, LDL-C and diabetes). Treatment compliance, age, follow-up time, sex, and number of anti-HTN were used as predictors in the model. The significance level adopted was $\mathrm{p}<0.05$.

\section{Results}

A total of 162 patients were included, with a mean age of $56.5 \pm 10.8$ years. The median follow-up time was 60 (IQR 40-109) months, and the date of the first observation was May 20th, 1991. The majority of the sample was female $(80.2 \%)$ and had no previous history of cardiovascular event (83.3\%). The study population characteristics are presented in Table 1.

BP, total cholesterol, LDL-cholesterol, triglycerides and HbA1C values showed a statistically significant trend to improve along the study visits. Oppositely, glomerular filtration rate values deteriorate throughout visits. Regarding lifestyle, alcohol consumption decreased across visits. Variables description along study visits are shown in Table 2.
Table 1 Study population baseline characteristics

\begin{tabular}{ll}
\hline $\mathrm{n}$ & 162 \\
Age (years) & $56.5( \pm 10.8)$ \\
Female & $130(80.2 \%)$ \\
Body mass index $\left(\mathrm{kg} / \mathrm{m}^{2}\right)$ & $30.9( \pm 5.4)$ \\
Cardiovascular event $^{\mathrm{a}}$ & $27(16.7 \%)$ \\
Predicted Framingham 10-year cardiovascular risk (\%) & $28.0( \pm 18.0)$ \\
Follow-up time V1-V2 (months) $^{\mathrm{b}}$ & $34(14-56)$ \\
Follow-up time V2-V3 (months) $^{\mathrm{b}}$ & $35(19-53)$ \\
Total follow-up time (months) $^{\mathrm{b}}$ & $60(40-109)$
\end{tabular}

Values given in means ( \pm SD) or $\mathrm{n}(\%)$

a Cardiovascular event-history of acute myocardial infarction, angina, cerebrovascular event, or revascularization (prior to study enrollment)

b Values give in median and interquartile range

Pharmacological treatment assessment showed a statistically significant growing trend in all variables along the study visits (number of anti-HTN, ACE inhibitors/ARBs, aspirin, statins, oral hypoglycemic agents, insulin, and treatment compliance) (Table 3).

Significant improvement trends in control of BP, LDLcholesterol and diabetes were also found across study visits. When control of these three conditions was assessed in combination, low control percentages were found in V1, V2 and V3 (1.2, 1.9 and 6.8\%, respectively), but also with a significant improvement trend $(\mathrm{p}<0.001)$. These results are shown in Fig. 1.

A comparison between patients who achieved treatment goals in V3 to those who did not achieve was conducted to find which factors may have influenced the different results between groups. Treatment compliance was higher among patients with BP, LDL-cholesterol and diabetes controlled in V3, and was the only variable with significant difference in the groups' comparison (Table 4).

Aiming to identify ways to improve the overall control of the patient with diabetes and HTN we built a linear regression model assessing the variables independently associated with the number of conditions (BP, LDL-cholesterol and diabetes) under control in the most recent visit. In this analysis, treatment compliance $(\beta$-coefficient $=1.20 ; 95 \%$ CI $1.07-1.34 ; \mathrm{p}<0.001)$ was the only variable positively associated with a better overall control of these patients (Table 5).

\section{Discussion}

This is the first study showing the results of a multidisciplinary treatment strategy addressing specifically the patient with diabetes and hypertension. A significant trend to improve laboratorial and clinical parameters was found. Despite the low number of patients with BP, LDL and $\mathrm{HbA} 1 \mathrm{C}$ controlled in combination along the study visits, a trend to improve this number was also found. 
Table 2 Variables description along study visits $(n=162)$, Goiânia-GO

\begin{tabular}{|c|c|c|c|c|}
\hline & Visit 1 & Visit 2 & Visit 3 & $p$ value $^{a}$ \\
\hline $\begin{array}{r}\text { Systolic BP } \\
(\mathrm{mmHg})\end{array}$ & $( \pm 19.9)$ & $136.2( \pm 20.2)$ & $133.5( \pm 18.6)$ & 0.002 \\
\hline $\begin{array}{l}\text { Diastolic BP } \\
(\mathrm{mmHg})\end{array}$ & $87.7( \pm 12.9)$ & $83.7( \pm 12.0)$ & $79.6( \pm 11.1)$ & $<0.001$ \\
\hline $\begin{array}{l}\text { Total choles- } \\
\text { terol (mg/ } \\
\mathrm{dL} \text { ) }\end{array}$ & 206.8 & $187.3( \pm 47.1)$ & $175.8( \pm 43.2)$ & $<0.001$ \\
\hline $\begin{array}{l}\text { LDL-choles- } \\
\text { terol (mg/ } \\
\mathrm{dL} \text { ) }\end{array}$ & $120.8( \pm 43.4)$ & $107.6( \pm 37.1)$ & $100.3( \pm 35.8)$ & $<0.001$ \\
\hline $\begin{array}{l}\text { HDL-choles- } \\
\text { terol (mg/ } \\
\mathrm{dL} \text { ) }\end{array}$ & 42.2 & $42.1( \pm$ & $43.2( \pm 9.9)$ & 0.207 \\
\hline $\begin{array}{l}\text { Triglycerides } \\
(\mathrm{mg} / \mathrm{dL})\end{array}$ & $220.0( \pm 160.7)$ & $200.7( \pm 173.7)$ & $176.4( \pm 125.7)$ & $<0.001$ \\
\hline $\begin{array}{l}\text { Fasting glu- } \\
\text { cose (mg/ } \\
\mathrm{dL})\end{array}$ & $149.6( \pm 65.8)$ & $137.0( \pm 49.7)$ & $147.8( \pm 53.6)$ & 0.515 \\
\hline $\mathrm{HbA1C}(\%)$ & $7.9( \pm 1.6)$ & $7.7( \pm 1.7)$ & $7.3( \pm 1.5)$ & $<0.001$ \\
\hline GFR (mL/min) & $78.3( \pm 21.5)$ & $72.8( \pm 21.1)$ & $66.3( \pm 21.0)$ & $<0.001$ \\
\hline Smoke & $8(4.9 \%)$ & $5(3.1 \%)$ & $5(3.1 \%)$ & 0.378 \\
\hline $\begin{array}{l}\text { Alcohol con- } \\
\text { sumption }\end{array}$ & $14(8.6 \%)$ & $7(4.3 \%)$ & $5(3.1 \%)$ & 0.026 \\
\hline $\begin{array}{l}\text { Sedentary } \\
\text { lifestyle }\end{array}$ & $20(12.4 \%)$ & $34(21.0 \%)$ & $26(16.1 \%)$ & 0.369 \\
\hline \multicolumn{5}{|c|}{ Predicted Framingham 10-year cardiovascular risk } \\
\hline Low & $19(11.7 \%)$ & $16(9.9 \%)$ & $15(9.3 \%)$ & 0.465 \\
\hline $\begin{array}{l}\text { Intermedi- } \\
\text { ate }\end{array}$ & $44(27.2 \%)$ & $53(32.7 \%)$ & 55 (33.9\%) & 0.188 \\
\hline High & $42(25.9 \%)$ & 40 (24.7\%) & 40 (24.7\%) & 0.798 \\
\hline Very high & $57(35.2 \%)$ & 53 (32.7\%) & $52(32.1 \%)$ & 0.556 \\
\hline
\end{tabular}

Values given in means ( \pm SD) or $\mathrm{n}(\%)$

GFR glomerular filtration rate

a $p$ value for trends across visits; statistically significant at $a<0.05$

Table 3 Medication variables description along study visits $(n=162)$, Goiânia-GO

\begin{tabular}{|c|c|c|c|c|}
\hline & Visit 1 & Visit 2 & Visit 3 & $p$ value ${ }^{a}$ \\
\hline Number of anti-HTN & $1.6( \pm 0.9)$ & $2.1( \pm 0.9)$ & $2.8( \pm 0.8)$ & $<0.001$ \\
\hline ACE inhibitors/ARBs & $102(63.0 \%)$ & $134(82.7 \%)$ & $150(92.6 \%)$ & $<0.001$ \\
\hline Aspirin & $27(16.7 \%)$ & $47(29.0 \%)$ & $52(32.1 \%)$ & 0.045 \\
\hline Statins & $46(28.4 \%)$ & $66(40.7 \%)$ & $98(60.5 \%)$ & $<0.001$ \\
\hline $\begin{array}{l}\text { Oral hypoglycemic } \\
\text { agents }\end{array}$ & 84 (51.9\%) & $146(90.1 \%)$ & $150(92.6 \%)$ & $<0.001$ \\
\hline Insulin & $12(7.4 \%)$ & $19(11.7 \%)$ & $33(20.4 \%)$ & 0.001 \\
\hline $\begin{array}{l}\text { Treatment compli- } \\
\text { ance }\end{array}$ & 55 (34.0\%) & 84 (51.9\%) & $111(68.9 \%)$ & $<0.001$ \\
\hline
\end{tabular}

Values given in means ( \pm SD) or $\mathrm{n}(\%)$

${ }^{a} p$ value for trends across visits; statistically significant at $a<0.05$
Additionally, control rates of each condition individually improved along the study. The only variable independently associated with a better overall control of the patient with T2DM and HTN was treatment compliance.

Although BP, total cholesterol, LDL-cholesterol, triglycerides and $\mathrm{HbA} 1 \mathrm{C}$ values showed a statistically significant trend to improve along the study visits, no changes in the predicted cardiovascular risk categories distribution were found. These results can be explained by the increasing age of the population along the study visits, since it is well stablished that age is a fundamental predictor of CVD risk [20].

A remarkable aspect of our results, which is clear from Fig. 1, is that blood pressure control was much better than the other factors. Although our multidisciplinary service has always focused on the overall patient management it is primarily specialized in hypertension treatment, which can explain this finding. Previous studies conducted in the same setting also showed good results in blood pressure management $[11,21]$ which must be simultaneously seen as extremely positive and as a call for action to improve management of other co-morbidities.

Morbidity in the diabetic patient is a consequence of both macro- and microvascular disease [22]. Once present, the progression of these complications can be slowed with drug interventions such as: ACE inhibitors or ARBs, aspirin, statins and optimization of oral hypoglycemic agents and insulin [23]. We found an increase in the number of individuals using ACE inhibitors/ARBs, aspirin, statins, oral hypoglycemic agents and insulin along the follow-up visits, suggesting an improvement in the pharmacological therapy prescribed. Similar results have been shown with the multidisciplinary treatment when addressing very elderly hypertensive patients [11].

The suboptimal management of patients with diabetes and HTN shown here by poor combined control of T2DM, HTN and dyslipidemia is consistent with previous reports from developed countries. The 1999-2000 US National Health and Nutrition Examination Survey (NHANES) found that only $7.3 \%$ of the adults with diabetes achieved the recommended therapeutic goals of HbA1c, BP and cholesterol [24], and this value improved, as shown along our follow-up, to $10.2 \%$ in the 2003-2006 NHANES survey [25]. Cross-sectional studies conducted in Poland [26] and China [27], less developed countries, found that among patients with diabetes and HTN, only 1.4 and $5.6 \%$ respectively, met all three targets. Even more concerning are the results from the randomized Steno-2 Study, conducted to evaluate the effect an intensified multifactorial intervention comprising behavior modification and polypharmacologic therapy aimed at several modifiable risk factors in patients with T2DM [28]. Although, the Steno-2 Study showed sustained beneficial effects with 


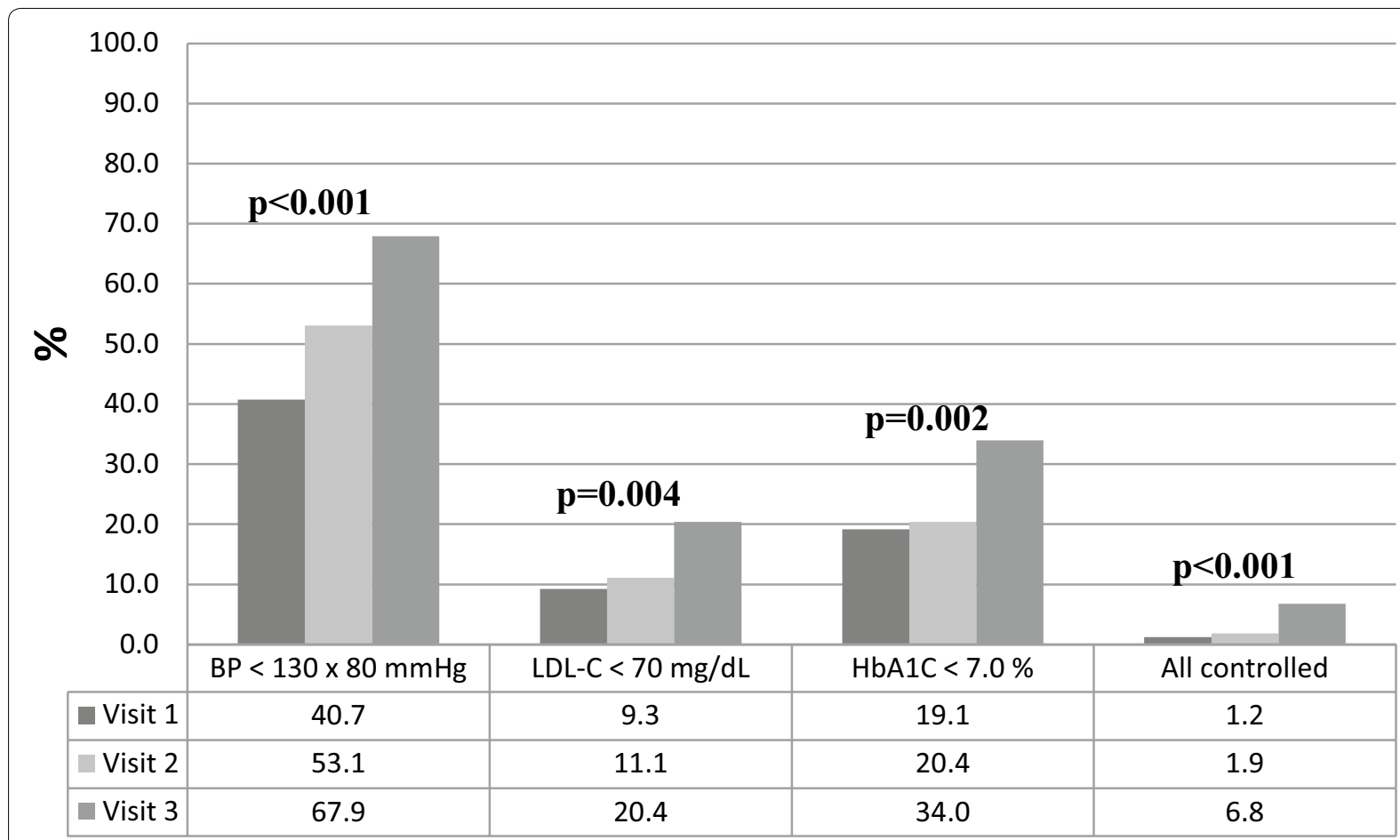

Fig. 1 Blood pressure, LDL-cholesterol and HbA1C under control along study visits ( $n=162$ ). Goiânia—GO. $p$ value for trends across visits; statistically significant at $a<0.05$

respect to vascular complications and on rates of cardiovascular deaths, it is notable that only one patient reached all five treatment goals (HbA1C, cholesterol, triglycerides, SBP and DBP) at the end of follow-up [28].

It is well established that $\mathrm{HbA1C}, \mathrm{BP}$ and LDL-cholesterol control in each patient with diabetes and HTN needs to be optimized [29]. Therefore, the linear regression model we built assessing the variables independently associated with the number of conditions (BP, LDLcholesterol and diabetes) under control, is a strength of our study that needs to be highlighted. In this model, treatment compliance was the only variable positively associated with management of patients with diabetes and HTN. Additionally to identifying treatment compliance as a variable associated with management of these patients, the simple and objective way we assessed compliance is another positive point. Instead of using complexes and sometimes unreliable methods to assess compliance [30], patients were asked if they have been compliant to drug treatments since their most recent visit to the center. This simple approach can be widely used in clinical practice and a negative answer to the question needs to warn and be a call for action for all health care providers dealing with these patients.

A potential limitation of this study is its design. We conducted a retrospectively single center with no control group study. Despite that, since all medical records are objective in this center, and the completion of its mandatory fields is exhaustively trained, the ability of generating reliable data is assured. Additionally, although a comparison with a control group would be ideal, the results we found can foster future studies and help informing the healthcare community about the optimal way to manage this specific population.

Another limitation is related to physical activity. Since we used just leisure physical activity in our definition, which accounts specifically for planned or formal physical activity (walking, running, cycling, swimming, strength training, etc.), daily physical activities were not considered. Therefore, the sedentary lifestyle results we found were probably overestimated.

Although more than $90 \%$ of patients with T2DM receive their routine care from primary care providers [31], a major unresolved controversy is the place of the generalist and the specialist in the treatment of these patients. Studies comparing care by specialists and generalists have generated conflicting findings [31-34]. In our case, care was delivered by a health care team in coordination with physicians from three different specialties: cardiology, nephrology and endocrinology. Notably, the presence of these three specialties is not required at the service concomitantly. Since we are reporting positive results the format adopted in our service can be a model for other centers handling patients diagnosed with both diabetes and HTN and aiming to implement a multidisciplinary strategy. 
Table 4 Patients who achieved treatment goals ${ }^{a}$ in visit 3 compared to those whom did not achieve $(n=162)$, GoiâniaGO

\begin{tabular}{|c|c|c|c|}
\hline & $\begin{array}{l}\text { Treatment goals in visit } 3 \\
\text { Not achieved }\end{array}$ & $\begin{array}{l}\text { Treatment goals in visit } 3 \\
\text { Achieved }\end{array}$ & $p$ value $^{\mathbf{b}}$ \\
\hline $\mathrm{N}$ & 151 & 11 & \\
\hline Female & $122(80.8 \%)$ & $8(72.7 \%)$ & 0.520 \\
\hline Age (years) & $62.57( \pm 11.54)$ & $68.00( \pm 10.15)$ & 0.130 \\
\hline Total follow-up time (months) ${ }^{c}$ & $60(37-105)$ & $64(51-150)$ & 0.210 \\
\hline Number of anti-HTN & $2.81( \pm 0.84)$ & $3.00( \pm 0.77)$ & 0.460 \\
\hline ACE inhibitors/ARBs & $141(93.4 \%)$ & $9(81.8 \%)$ & 0.160 \\
\hline Body mass index $\left(\mathrm{kg} / \mathrm{m}^{2}\right)$ & $30.77(5.61)$ & $27.48(3.86)$ & 0.057 \\
\hline Insulin & $33(21.9 \%)$ & $0(0.0 \%)$ & 0.082 \\
\hline Oral hypoglycemic agents & $141(93.4 \%)$ & $9(81.8 \%)$ & 0.160 \\
\hline Aspirin & $47(31.1 \%)$ & $5(45.5 \%)$ & 0.330 \\
\hline Statins & $94(62.3 \%)$ & $4(36.4 \%)$ & 0.090 \\
\hline Cardiovascular event $^{d}$ & $48(31.8 \%)$ & $3(27.3 \%)$ & 0.760 \\
\hline Sedentary lifestyle & $25(16.6 \%)$ & $1(9.1 \%)$ & 0.510 \\
\hline Smoke & $5(3.3 \%)$ & $0(0.0 \%)$ & 0.540 \\
\hline Alcohol consumption & $5(3.3 \%)$ & $0(0.0 \%)$ & 0.540 \\
\hline Treatment compliance & $100(66.7 \%)$ & $11(100.0 \%)$ & 0.021 \\
\hline \multicolumn{4}{|c|}{ Predicted Framingham 10-year cardiovascular risk } \\
\hline Low & $14(9.3 \%)$ & $1(9.1 \%)$ & 0.980 \\
\hline Intermediate & $50(33.1 \%)$ & $5(45.4 \%)$ & 0.400 \\
\hline High & $38(25.2 \%)$ & $2(18.2 \%)$ & 0.600 \\
\hline Very high & 49 (32.4\%) & $3(27.3 \%)$ & 0.720 \\
\hline
\end{tabular}

Values given in means $( \pm S D)$ or $n(\%)$

a Blood pressure $<130 \times 80 \mathrm{mmHg}$, LDL-cholesterol $<70 \mathrm{mg} / \mathrm{dL}, \mathrm{HbA} 1 \mathrm{C}<7.0 \%$

b Statistically significant at $a=0.05$

c Values give in median and interquartile range

d Cardiovascular event-history of acute myocardial infarction, angina, cerebrovascular event, or revascularization

Table 5 Linear regression coefficients for the number of diseases under control $^{\mathrm{a}}(\mathrm{n}=162)$, Goiânia-GO

\begin{tabular}{lllr}
\hline Variables & $\boldsymbol{\beta}$-coefficient & [95\% Cl] & $\boldsymbol{p}$ value $^{\mathbf{b}}$ \\
\hline Treatment compliant & 1.20 & 1.07 to 1.34 & $<0.001$ \\
Age & 0.00 & -0.01 to 0.01 & 0.555 \\
Follow-up time & 0.01 & -0.02 to 0.03 & 0.869 \\
Male sex & 0.09 & -0.22 to 0.41 & 0.543 \\
Number of anti-HTN & 0.07 & -0.08 to 0.22 & 0.336 \\
\hline
\end{tabular}

a Blood pressure $<130 \times 80 \mathrm{mmHg}$, LDL-cholesterol $<70 \mathrm{mg} / \mathrm{dL}, \mathrm{HbA} 1 \mathrm{C}<7.0 \%$

b Statistically significant at $\mathrm{a}=0.05$

\section{Conclusion}

Multidisciplinary treatment of patients with diabetes and hypertension has shown significant improvements in clinical and laboratory parameters, despite ageing of the population evaluated. Although combined control of HbA1C, BP and LDL-cholesterol increased along followup, management of all these three conditions needs to improve, and focus on treatment compliance should be given to attain this goal.

\section{Abbreviations}

ABPM: ambulatory BP monitoring; ACE: angiotensin converter enzyme; AMl: acute myocardial infarction; ARB: inhibitors or angiotensin receptor blocker; BMI: body mass index; BP: blood pressure; CVD: cardiovascular disease; DBP: diastolic blood pressure; T2DM: type 2 diabetes mellitus; HbA1C: hemoglobin A1C; HDL: high density lipoprotein cholesterol; HTN: hypertension; LDL: low density lipoprotein cholesterol; SBP: systolic blood pressure; TC: total cholesterol; TG: serum triglycerides; V1: first visit; V2: intermediate visit; V3: most recent visit.

\section{Authors' contributions}

All authors have made substantial contributions to conception and design, acquisition of data, analysis and interpretation of data, have been involved in drafting the manuscript and revising it critically for important intellectual content to be published. All authors read and approved the final manuscript.

\section{Author details}

${ }^{1}$ Hypertension League, Federal University of Goias, $1^{\text {a }}$ Avenida, S/N.-Setor Universitário, Goiânia, GO CEP 74085-300, Brazil. ${ }^{2}$ Division of Cardiovascular Medicine, Brigham \& Women's Hospital, 75 Francis Street, Boston, MA 02115, USA. ${ }^{3}$ Center for Health Decision Science, Harvard TH Chan School of Public Health-Department of Health Policy and Management, 718 Huntington Avenue, 2nd Floor, Boston, MA 02115, USA.

\section{Acknowledgements}

Not applicable. 


\section{Competing interests}

The authors declare that they have no competing interests.

\section{Availability of data and materials}

The datasets analyzed during the current study are available from the corresponding author on reasonable request.

\section{Consent for publication}

Not applicable.

\section{Ethics approval and consent to participate}

This study was reviewed and approved by the Research Ethics Committee in Human Medical Research from the Federal University of Goias Clinics Hospital (Protocol No 1.822.180 of November 16th, 2016).

\section{Funding}

The project received no funding.

\section{Publisher's Note}

Springer Nature remains neutral with regard to jurisdictional claims in published maps and institutional affiliations.

Received: 12 December 2017 Accepted: 29 December 2017

Published online: 08 January 2018

\section{References}

1. Turner RC, Holman RR, Matthews DR, Bassett PA, Coster R, Stratton IM Cull C, Peto R, Frighi V, Kennedy I, Manley S. Hypertension in Diabetes Study (HDS): I. Prevalence of hypertension in newly presenting type 2 diabetic patients and the association with risk factors for cardiovascular and diabetic complications. J Hypertens. 1993;11(3):309-17.

2. Grossman A, Grossman E. Blood pressure control in type 2 diabetic patients. Cardiovasc Diabetol. 2017;16(1):3

3. Chew BH, Mastura I, Shariff-Ghazali S, Lee PY, Cheong AT, Ahmad Z, Taher SW, Haniff J, Mustapha FI, Bujang MA. Determinants of uncontrolled hypertension in adult type 2 diabetes mellitus: an analysis of the Malaysian diabetes registry 2009. Cardiovasc Diabetol. 2012;11(1):54.

4. Pickering TG. The natural history of hypertension: prehypertension or masked hypertension? J Clin Hypertens. 2007;9(10):807-10.

5. Phillips LS, Ratner RE, Buse JB, Kahn SE. We can change the natural history of type 2 diabetes. Diabetes Care. 2014;37(10):2668.

6. Mancia G, Fagard R, Narkiewicz K, Redon J, Zanchetti A, Böhm M, Christiaens T, Cifkova R, De Backer G, Dominiczak A, et al. 2013 ESH/ESC guidelines for the management of arterial hypertension. Eur Heart J. 2013;34(28):2159.

7. Ryden L, Grant PJ, Anker SD, Berne C, Cosentino F, Danchin N, Deaton C, Escaned J, Hammes HP, Huikuri H, et al. ESC Guidelines on diabetes, prediabetes, and cardiovascular diseases developed in collaboration with the EASD: the Task Force on diabetes, pre-diabetes, and cardiovascular diseases of the European Society of Cardiology (ESC) and developed in collaboration with the European Association for the Study of Diabetes (EASD). Eur Heart J. 2013:34(39):3035-87.

8. Standards of Medical Care in. Diabetes-2017: summary of revisions. Diabetes Care. 2017:40(Suppl 1):S4-5.

9. Whelton PK, Carey RM, Aronow WS, Casey DE, Collins KJ, Dennison Himmelfarb C, DePalma SM, Gidding S, Jamerson KA, Jones DW, et al. ACC/ AHA/AAPA/ABC/ACPM/AGS/APhA/ASH/ASPC/NMA/PCNA Guideline for the prevention, detection, evaluation, and management of high blood pressure in adults. J Am College Cardiol. 2017. https://doi.org/10.1016/j. jacc.2017.11.006 (Epub ahead of print)

10. Pereira DA, Costa NMdSC, Sousa ALL, Jardim PCBV, Zanini CRdO. The effect of educational intervention on the disease knowledge of diabetes mellitus patients. Revista Latino-Americana de Enfermagem. 2012;20:478-85.

11. Jardim LMSSV, Jardim TV, de Souza WK, Pimenta CD, Sousa ALL, Jardim PCBV. Multiprofessional treatment of high blood pressure in very elderly patients. Arquivos Brasileiros de Cardiologia. 2017;108(1):53-9.

12. Malachias MVB, Gomes MAM, Nobre F, Alessi A, Feitosa AD, Coelho EB. 7th Brazilian guideline of arterial hypertension: chapter 2-diagnosis and classification. Arq Bras Cardiol. 2016;107(3 Suppl 3):7-13.
13. Diretrizes da Sociedade Brasileira de Diabetes (2015-2016). In: Edited by Diabetes SBd: Grupo Editorial Nacional; 2016.

14. Levey AS, Bosch JP, Lewis JB, Greene T, Rogers N, Roth D. A more accurate method to estimate glomerular filtration rate from serum creatinine: a new prediction equation. Modification of Diet in Renal Disease Study Group. Ann Intern Med. 1999;130(6):461-70.

15. Friedewald WT, Levy RI, Fredrickson DS. Estimation of the concentration of low-density lipoprotein cholesterol in plasma, without use of the preparative ultracentrifuge. Clin Chem. 1972;18(6):499-502.

16. D’Agostino RB Sr, Vasan RS, Pencina MJ, Wolf PA, Cobain M, Massaro JM, Kannel WB. General cardiovascular risk profile for use in primary care: the Framingham Heart Study. Circulation. 2008;117(6):743-53.

17. Malachias MVB, Amodeo C, Paula RB, Cordeiro Júnior AC, Magalhães L, Bodanese LC. 7(th) Brazilian guideline of arterial hypertension: chapter 8-hypertension and associated clinical conditions. Arquivos Brasileiros de Cardiologia. 2016;107(3 Suppl 3):44-8.

18. Faludi AA, Izar MCO, Saraiva JFK, Chacra APM, Bianco HT, Afiune AN, Bertolami A, Pereira AC, Lottenberg AM, Sposito AC, et al. Atualização da Diretriz Brasileira de Dislipidemias e Prevenção da Aterosclerose - 2017. Arq Bras Cardiol. 2017:109(2 Supl 1):1-76.

19. Cuzick J. A Wilcoxon-type test for trend. Stat Med. 1985;4(1):87-90.

20. Dhingra R, Vasan RS. Age as a cardiovascular risk factor. Med Clin N Am. 2012;96(1):87-91.

21. Sousa AC, Jardim TV, Costa TO, Magalhães FG, Montelo MPM, Souza WKB, Jardim PCBV, Sousa ALL. Hypertensive diabetic patients: incidence of cardiovascular and renal outcomes in a historical cohort over 11 years. Diabetol Metab Syndr. 2017;9(1):98.

22. Harris MI, Klein R, Welborn TA, Knuiman MW. Onset of NIDDM occurs at least 4-7 year before clinical diagnosis. Diabetes Care. 1992;15(7):815.

23. Gregg EW, Li Y, Wang J, Rios Burrows N, Ali MK, Rolka D, Williams DE, Geiss L. Changes in diabetes-related complications in the United States, 1990-2010. N Engl J Med. 2014;370(16):1514-23.

24. Saydah SH, Fradkin J, Cowie CC. Poor control of risk factors for vascular disease among adults with previously diagnosed diabetes. JAMA. 2004;291(3):335-42.

25. Wong K, Glovaci D, Malik S, Franklin SS, Wygant G, lloeje U, Kan H, Wong ND. Comparison of demographic factors and cardiovascular risk factor control among U.S. adults with type 2 diabetes by insulin treatment classification. J Diabetes Complicat. 2012;26(3):169-74.

26. Bala MM, Placzkiewicz-Jankowska E, Topor-Madry R, Lesniak W, Jaeschke R, Sieradzki J, Grzeszczak W, Banasiak W. Is newly diagnosed type 2 diabetes treated according to the guidelines? Results of the Polish ARETAEUS1 study. Pol Arch Med Wewn. 2011;121(1-2):7-17.

27. Ji L, Hu D, Pan C, Weng J, Huo Y, Ma C, Mu Y, Hao C, Ji Q, Ran X, et al. Primacy of the $3 B$ approach to control risk factors for cardiovascular disease in type 2 diabetes patients. Am J Med. 2013;126(10):925.e911-22.

28. Gæde P, Lund-Andersen $\mathrm{H}$, Parving $\mathrm{H}-\mathrm{H}$, Pedersen $\mathrm{O}$. Effect of a multifactorial intervention on mortality in type 2 diabetes. N Engl J Med. 2008:358(6):580-91.

29. Gæde P, Vedel P, Larsen N, Jensen GVH, Parving H-H, Pedersen O. Multifactorial intervention and cardiovascular disease in patients with type 2 diabetes. N Engl J Med. 2003;348(5):383-93.

30. García-Pérez L-E, Álvarez M, Dilla T, Gil-Guillén V, Orozco-Beltrán D. Adherence to therapies in patients with type 2 diabetes. Diabetes Ther. 2013:4(2):175-94.

31. Zgibor JC, Songer TJ, Kelsey SF, Drash AL, Orchard TJ. Influence of health care providers on the development of diabetes complications: long-term follow-up from the Pittsburgh Epidemiology of Diabetes Complications Study. Diabetes Care. 2002;25(9):1584-90.

32. Ho M, Marger M, Beart J, Yip I, Shekelle P. Is the quality of diabetes care better in a diabetes clinic or in a general medicine clinic? Diabetes Care. 1997:20(4):472-5.

33. Greenfield S, Rogers W, Mangotich M, Carney MF, Tarlov AR. Outcomes of patients with hypertension and non-insulin dependent diabetes mellitus treated by different systems and specialties. Results from the medical outcomes study. JAMA. 1995:274(18):1436-44.

34. Verlato G, Muggeo M, Bonora E, Corbellini M, Bressan F, de Marco R. Attending the diabetes center is associated with increased 5-year survival probability of diabetic patients: the Verona Diabetes Study. Diabetes Care. 1996:19(3):211-3. 